\title{
Creating favorable conditions for increased quantity of high-quality clinical studies in surgery
}

\author{
Tian Yang ${ }^{1}$, Wan Yee Lau ${ }^{1,2}$, Feng Shen ${ }^{1}$ \\ ${ }^{1}$ Department of Hepatic Surgery, The Eastern Hepatobiliary Surgery Hospital, Second Military Medical University (Naval Medical University), \\ Shanghai 200438, China; ${ }^{2}$ Faculty of Medicine, The Chinese University of Hong Kong, Hong Kong, SAR, China \\ Correspondence to: Prof. Feng Shen, MD, PhD. Department of Hepatic Surgery, the Eastern Hepatobiliary Surgery Hospital, Second Military Medical \\ University (Naval Medical University), No. 225, Changhai Road, Shanghai 200438, China. Email: shenfengehbh@sina.com; Prof. Wan Yee Lau, \\ MD, FRCS. Department of Hepatic Surgery, the Eastern Hepatobiliary Surgery Hospital, Second Military Medical University (Naval Medical \\ University), Shanghai 200438, China; Faculty of Medicine, the Chinese University of Hong Kong, Shatin, New Territories, Hong Kong, SAR, \\ China. Email: josephlau@surgery.cuhk.edu.hk. \\ Provenance and Peer Review: This article was commissioned by the editorial office, Hepatobiliary Surgery and Nutrition. The article did not undergo \\ external peer review.
}

Submitted Mar 12, 2020. Accepted for publication Mar 29, 2020.

doi: 10.21037/hbsn.2020.04.04

View this article at: http://dx.doi.org/10.21037/hbsn.2020.04.04

Nowadays, surgeons in China, especially those who are working in teaching hospitals affiliated to universities, concentrate their research efforts in basic researches mainly because these researches can generate scientific articles in journals of high impact factors which are essential for career advancement, job promotion and securing research grants. Clinical surgical research is generally considered as less important because the influence of generating evidence on clinical practice has not been fully recognized by clinicians in China. Furthermore, there is a relative lack of financial and administrative support for clinical surgical research. Finally, surgeons in China in general need to further improve the knowledge and means to conduct good clinical research.

This commentary mainly focuses on these issues.

\section{Fully acknowledge the importance of clinical surgical research}

Even with rapid advances in surgery in the recent few decades, it is undeniable that only a fraction of clinical problems has been resolved. The purpose of clinical research in surgery is to establish reliable evidences that enable surgeons to apply to improve their surgical practices. Proper update and advice on surgical knowledge and skills would benefit patients, especially those suffering from malignant diseases. Although oncological surgery is currently quite well-developed, there are still a lot of rooms for improvement. If surgeons are satisfied with carrying out routine and repetition surgical procedures day in and day out, there will not be any further advances in surgery. Surgery advances through innovations in ideas and techniques through surgical research.

Teaching hospitals are responsible for generating innovations. Any new treatment idea or technique generated through clinical research should be broadly promoted to other clinicians so that more patients can benefit.

\section{To actively create favorable conditions for clinical surgical research}

Most surgeons working in China are currently overloaded by their daily clinical duties. As a consequence, extra efforts have to be paid in conducting clinical research. To develop a passion for clinical research is the key to overcome all the hurdles in research. The biggest reward for a surgeonscientist is to produce research results which benefit patients. This reward brings more enthusiasm to do more researches, thus forming a virtuous circle. Throughout the history of surgery, most successful surgeon-scientists have been overloaded with work duties, and their initial research paths have not been smooth. Yet, their great passions for clinical research have been driving them through all 
difficulties to overcome all hurdles.

Well-designed clinical studies have many steps. The first step is to collect clinicopathological data of patients to establish a database. Then, the knowledge in statistics has to be mastered. Surgeons should also actively participate in the training in Good Clinical Practice (GCP) and learn to thoroughly review the medical literature on the topics related to their research interest. Currently, funding for clinical research from the government is relatively insufficient, but it should not stop surgeons from launching their research works. Surgeons can cooperate with colleagues from other centers to increase sample sizes in retrospective or prospective cohort studies, cooperate with basic researchers to conduct translational medical research and coordinate with pharmaceutical enterprises to conduct clinical researches on drugs. To keep an open mind and to be able to gather better financial, human and data resources are crucial in good clinical researches.

\section{Conducting high-quality clinical research in surgery}

The prerequisites for a high-quality clinical study are to minimize biases that potentially affect outcomes and to maximize reliability of results of the study. The following points may be important to achieve these aims:

(I) To solve a clinical problem as a scientific problem. Dedication to clinical works helps to resolve meaningful clinical problems in a scientific way. It is important to treat any clinical problem as a scientific problem. Conducting researches to resolve a clinical problem may bring innovative results. Before starting on any research, surgeons must study, consider, discuss thoroughly, and clarify whether the research project has a practical and meaningful value. Ask the following important questions: Whether the problem has been solved in previous studies? Can the problem be solved with the resources and conditions currently available? A lesson which has been learned in many previously failed clinical studies is: do not have any unrealistic "false hope" on research outcomes.

(II) Fill in the gaps in guidelines or consensus. In addition to creating original knowledge or treatment methods as mentioned above, improving previous works by other surgeons is also a good direction. Find controversial or unclear topics by carefully reading published guidelines or consensus.
Innovative research directions to achieve impactful results can be obtained by revising established guidelines or consensus.

(III) Critically evaluate previous works by other surgeons. Carefully read the representative works by other surgeons. Find out the deficiencies in their study methods, data collection, endpoint indicators or statistical analysis. In particular, test to see whether any causal relationship stands in their research content and conclusion. Young surgeons may find this especially helpful in improving the quality of their research. Chapter 8 of the Sabiston Textbook of Surgery (20th Edition) has a thorough explanation on this point (1).

(IV) Make use of basic research outcomes to conduct translational clinical researches. Precision medicine has currently developed rapidly based on various "omics", and "molecular surgery". Translating basic into clinical research can generate excellent research articles. A good example is in surgical treatment of cancer. A number of treatments based on the traditional staging systems have now been replaced by new molecular subtyping.

(V) Plant fruit trees instead of corps. Fruit trees take years to grow. However, once they mature, fruits can be repeatedly harvested on a yearly basis. On the other hand, corns can only be harvested one time. To produce high-quality clinical researches should follow the way in planting a fruit tree, and then to develop the planted fruit trees into a forest. This requires a good foundation and long-term planning. Instead of frequent shifting research directions, one should conduct researches around some topics in a systematic manner, which is crucial in improving the quality and quantity of researches, thus generating impactful results (2).

(VI) Let the peers know your research works. Most clinical studies are published in journals. Good research writing is part of the quality of a good research study. Surgeons should widely read scientific articles, learn to write high-quality papers, and publish more research works so that more peers get to know your research works.

In the article "Behavior, Work, and Knowledge", Professor Fazu Qiu suggested surgeons should be very meticulous in doing researches (3). Establishing rigorous research criteria is important for a surgeon to carry out high-quality researches and to help him/her to establish 
good reputation in the surgical field.

\section{Acknowledgments}

Funding: None.

\section{Footnote}

Conflicts of Interest: All authors have completed the ICMJE uniform disclosure form (available at https://hbsn.amegroups. com/article/view/10.21037/hbsn.2020.04.04/coif). WYL serves as an unpaid editorial board member of Hepatobiliary Surgery and Nutrition. The other authors have no conflicts of interest to declare.

Ethical Statement: The authors are accountable for all aspects of the work in ensuring that questions related to the accuracy or integrity of any part of the work are appropriately investigated and resolved.

Open Access Statement: This is an Open Access article distributed in accordance with the Creative Commons Attribution-NonCommercial-NoDerivs 4.0 International License (CC BY-NC-ND 4.0), which permits the noncommercial replication and distribution of the article with the strict proviso that no changes or edits are made and the original work is properly cited (including links to both the formal publication through the relevant DOI and the license). See: https://creativecommons.org/licenses/by-nc-nd/4.0/.

\section{References}

1. Simianu V, Farjah F, Flum D. Evidence-Based Surgery: Critically Assessing Surgical Literature. In: Townsend C, Beauchamp D, Evers M, et al. Sabiston Textbook of Surgery: the biological basis of modern surgical practice 20th Edition 2016:173-86.

2. Zhou WP, Shen F, Cheng SQ, et al. The way of thinking decides exit and the innovation leads future: practice and implementation of Academician Lau Wan Yee's research ideas. Chin J Digest Surg 2018;17:51-4.

3. Qiu FZ. Behavior, Work, and Knowledge. Chin Med Ethics 2008;1:3-5.
Cite this article as: Yang T, Lau WY, Shen F. Creating favorable conditions for increased quantity of high-quality clinical studies in surgery. HepatoBiliary Surg Nutr 2020;9(3):330332. doi: $10.21037 / \mathrm{hbsn} .2020 .04 .04$ 